\title{
Propostas para "uma nova maneira de viver": Vilanova Artigas e a ação habitacional da CECAP (1967-1973)
}

\section{Michele Aparecida Siqueira Dias}

Graduanda em História pela Escola de Filosofia, Letras e Ciências Humanas da Universidade Federal de São Paulo, Escola de Filosofia, Letras e Ciências Humanas, Estrada do Caminho Velho, 333, Jd. Nova Cidade, Guarulhos, SP, CEP 07252-312, (11) 5576-4848, dias.micheleas@gmail.com

\section{Resumo}

O presente artigo pretende revisitar as obras do arquiteto João Batista Vilanova Artigas (1915 - 1985) para a autarquia Caixa Estadual de Casas para o Povo (CECAP), buscando evidenciar as propostas elaboradas pelo arquiteto, bem como a escolha deste profissional para a realização destas obras. Buscaremos evidenciar como as ações políticas da CECAP refletiram na trajetória da construção dos projetos dos conjuntos habitacionais para as cidades de Guarulhos (1967), Americana (1972) e Jundiaí (1973).

Palavras-chave: CECAP, conjuntos habitacionais, Vilanova Artigas.

प1

CECAP não constrói apenas casas. Constrói uma nova maneira de viver" foi o título de uma das propagandas veiculadas pela autarquia Caixa Estadual de Casas para o Povo, a CECAP, durante a década de 1970, no jornal Folha de S. Paulo. O leitor desta propaganda é imediatamente levado a pensar que "nova maneira de viver" é esta, porém logo abaixo do título, é possível notar a fotografia dos conjuntos habitacionais da autarquia, dois deles, projetados pelo arquiteto paranaense João Batista Vilanova Artigas (1915 - 1985).

Artigas formou-se engenheiro-arquiteto em 1937 pela Escola Politécnica da Universidade de São Paulo. Ainda estudante, estagiou no escritório de Oswaldo Arthur Bratke e Carlos Botti, além de, após o término dos estudos, fundar uma construtora com um colega da Politécnica, a Marone \& Artigas. Foi docente da Faculdade de Arquitetura e Urbanismo, um dos integrantes que fundaram o Instituto dos Arquitetos do Brasil - seção São Paulo (IAB-SP) e militante do Partido Comunista do Brasil (PCB), que influenciou diretamente na sua produção arquitetônica. Vilanova Artigas, como um dos principais arquitetos e pesquisadores soluções construtivas e de materiais, propôs, durante sua trajetória profissional e pessoal, a defesa da arquitetura como transformação da sociedade e a função social do arquiteto (BUZZAR, 2014, p. 12).

Pareceu-nos importante revisitar a produção habitacional de Artigas, produzida sob responsabilidade do Estado, marcada pela contribuição do arquiteto na ação habitacional promovida pela autarquia CECAP - um órgão que apesar de criado no final da década de 1940, começou a funcionar, de fato, apenas no final da década de 1960, período em que o tema da habitação social havia entrado novamente na agenda dos arquitetos, em discussões nos Institutos, e principalmente na agenda política do novo regime. Pretendemos então, mostrar as propostas arquitetônicas elaboradas por Artigas, procurando evidenciar os motivos pelos quais o arquiteto foi escolhido para elaboração destes projetos e quais foram os motivos pelos quais as obras não foram concluídas plenamente ou acabaram apenas no projeto. 


\section{Um órgão habitacional para São Paulo: a Caixa Estadual de Casas para o Povo (CECAP)}

1 Autarquia é um termo jurídico, definido pelo dicionário Aurélio como "Entidade autônoma, auxiliar e descentralizada da administração pública, sujeita à fiscalização e à tutela do Estado, com patrimônio constituído de recursos próprios, e cujo fim é executar serviços de caráter estatal ou interessantes à coletividade".

2 Estas informações foram retiradas do debate realizado com o arquiteto Ruy Gama sobre a atuação da CECAP e construção do conjunto de Guarulhos, em 1968, e transcrito no volume $\mathrm{n}$. 4 da Revista Desenho, da Faculdade de Arquitetura e Urbanismo da Universidade de São Paulo. Gama era, na época, assistente do superintendente da CECAP, José Magalhães Prado, comissionado na CECAP pelo Departamento de Obras Públicas do Estado de São Paulo.

3 O governador Roberto de Abreu Sodré sancionou uma série de medidas para o desenvolvimento industrial, como parte de um projeto político do Estado. Uma das primeiras medidas administrativas foi, segundo o historiador Edson Trajano Vieira (2009), a divisão do estado em 10 regiões administrativas, visando a eficiência do governo para o desenvolvimento, não apenas econômico (baseado na instalação de indústrias) mas também social, com a instalação de equipamentos públicos para a população. Sodré também criou vários mecanismos para distribuir a renda no Estado de São Paulo e descongestionar a área metropolitana, como, por exemplo, criação do Grupo de Análise Territorial (GAT) e o Grupo de Descentralização Industrial (GDI), além de dar incentivos fiscais para a industrialização no eixo estabelecido por estes grupos (VIEIRA, 2009, p. 91).
A Caixa Estadual de Casas Para o Povo (CECAP) foi uma autarquia ${ }^{1}$ criada em 1949, durante a gestão do governador Adhemar de Barros Pereira, após o fechamento do escritório regional da Fundação Casa Popular, em São Paulo (BONDUKI, 2004, p. 121). Ligada à Secretaria do Trabalho, Indústria e Comércio, destinava-se a promover moradia para a população operária sindicalizada do Estado, porém permaneceu inoperante até a década de 1960. A razão dada pela própria CECAP para a sua lacuna operacional está na desestimulação do mercado rentista habitacional causada pela série de Leis do Inquilinato (1942 - 1964).

A autarquia foi regulamentada no início do ano de 1964, antes do golpe militar e da criação do Banco Nacional de Habitação (BNH), pelo mesmo governador que a criou. Entre o ano de 1964 e 1966, suas atividades se resumiam em arrecadar fundos por meio de impostos de transação de imóveis, impostos de vendas e destinação orçamentária². Após este período, a CECAP iniciou o processo de aplicar seus fundos em conjuntos habitacionais, com apoio da Caixa Econômica do Estado de São Paulo (CEESP), órgão gestor do fundo habitacional, que possuía o objetivo financiar a produção habitacional, comercialização e aquisição de terrenos, dentro da faixa de aquisição dos recursos e normas impostas pelo Sistema Financeiro de Habitação (SFH).

O ano de 1967 marcou a primeira empreitada de construções da CECAP no interior paulista. Os conjuntos habitacionais construídos foram descritos pelo arquiteto Ruy Gama como casas de até $60 \mathrm{~m}^{2}$, com projetos simples (elaborado pelo setor de engenharia da (ECAP) e obras de contratação barata e instalados em terrenos doados pelas prefeituras municipais ou de particulares, com uma intervenção das prefeituras, sendo assim, a doação não era computada no custo da casa, garantindo um preço acessível à população trabalhadora. Como contrapartida para a construção de casas, a CECAP esperava que as prefeituras intervissem com a instalação de recursos como rede elétrica, água, esgoto, além de também garantir uma boa localização para o empreendimento e instalação de equipamentos como escolas, abastecimento e serviços em geral. De modo geral, até a dissolução da autarquia CECAP, ela funcionou deste mesmo modo: a principal função da autarquia era estabelecer um acordo com as Prefeituras Municipais do Estado de São Paulo para viabilidade de instalação de conjuntos habitacionais. A CECAP se encarregava do projeto e da comercialização das unidades habitacionais, porém necessitava do apoio financeiro da CEESP e das Prefeituras Municipais para instalação dos recursos básicos para habitabilidade das unidades.

No final do ano de 1966, o recém nomeado Governador do Estado, Roberto Abreu Sodré3, notou que na distribuição de cargos públicos para seus correligionários, havia esquecido seu amigo e companheiro político, José Magalhães Prado. Para remediar a ação, o então Governador ofereceu a José Magalhães a superintendência da CECAP.

Como superintendente da autarquia, Prado iniciou as referidas obras de pequenos conjuntos no interior do Estado, elaborou critérios para aquisição das unidades habitacionais, favorecendo a classe operária sindicalizada e nomeou como seu assessor o arquiteto Ruy Gama (CUNHA, 2009, p. 75). Tal nomeação foi extremamente importante para o percurso da CECAP, pois, devido algumas experiências previamente mal sucedidas no interior do Estado, onde as prefeituras não conseguiram fazer intervenções para instalação de equipamentos públicos junto as construções, decidiu-se procurar locais para a instalação de conjuntos de grande porte em regiões com grande concentração da classe operária, e também pelo déficit habitacional que era mais grave na região metropolitana, Prado apresentou a proposta de um conjunto habitacional "modelo" de grande porte, com o intuito de dar uma "nova feição" ao cenário da habitação social no Estado de São Paulo.

Esta nova política da CECAP ia de encontro com os planos de legitimação do momento político vivido no país, no qual o desenvolvimento econômico era um de seus principais pilares (NAPOLITANO, 2014, p. 149). As ações do governador Abreu Sodré em delegar uma autarquia "esquecida", construir um grande conjunto habitacional em uma das principais cidades da região metropolitana de São Paulo, com um grande número de operários, estavam dentro do plano de ações para interiorização do desenvolvimento industrial, do qual o então governador e a CECAP focaram a sua atenção. 
4 Estas informações foram retiradas de um Processo Administrativo arquivado na Prefeitura Municipal de Guarulhos "Requerente: Francisca Maria de Freitas e outros. "Solicita medidas urgentes a fim de que famílias residentes em barracos CECAP sejam transferidas". Departamento de Microfilmagem de Guarulhos.

5 Com o falecimento de José (Zezinho) Magalhães Prado faleceu em 1969, O conjunto habitacional de Cumbica acabou recebendo seu nome. Após Prado, a superintendência da CECAP foi assumida por Juvenal Juvêncio (CERÁVOLO, 2007, p. 67).
Para a construção do primeiro conjunto de grande porte da autarquia, a CEESP possuía um terreno próximo ao vetor de industrialização da cidade de Guarulhos, cortado pela Rodovia Presidente Dutra (antiga Estrada de Rodagem SP - RJ), e nos limites da Base Aérea de Cumbica. A posse do terreno foi transferida para a CECAP por meio de um processo de desapropriação movido pela autarquia, em agosto de 1967. O registro da superfície era de 1.780.000.000 m² (130 hectares), com uma área de várzea do Rio Baquirivú-Guaçu e com ocupações irregulares e precárias.

Por ser uma área próxima à várzea de um rio e própria para o cultivo, o terreno atraiu famílias que não possuíam renda fixa e que no solo encontraram oportunidade de uma pequena renda familiar. Estas famílias eram formadas, em sua maioria, por migrantes de outras regiões do país (sendo que relatos orais revelam a presença de imigrantes japoneses). Entre os anos de 1969 e 1970 a CECAP promoveu a transferência das famílias que habitavam o terreno para casas pré-fabricadas em madeira, de três cômodos simples, situadas em terreno insalubre na Rua Avelino Loquetti, próximo ao futuro conjunto habitacional, localizada entre as indústrias Asea Elétrica S/A e a Metalúrgica Stella SEA, uma das indústrias pioneiras na cidade. ${ }^{4}$

A insatisfação dos moradores com as condições fornecidas pela CECAP resultou em um abaixoassinado contra a CECAP para a Prefeitura de Guarulhos, em dezembro do mesmo ano, com 43 assinaturas. O então prefeito da cidade, Waldomiro Pompeo, enviou um oficio ao superintendente da CECAP, expondo o problema e pedindo que a autarquia transferisse as habitações para um terreno salubre, transcrito a seguir:

No referido local foram construídos pela CECAP, pavilhões de madeira, cada um dividido em 5 casas de 3 compartimentos, com o fim de abrigar 36 famílias oriundas de diferentes Estados da federação e desalojados de suas habitações primitivas situadas em terrenos da Caixa Econômica, próximos ao local. Os referidos pavilhões são de construção simples, aceitáveis como moradia provisória, porem situadas em terreno de péssimas condições, alagadiço e baixo, não existindo fossas sépticas, somente fossas negras que em virtude das condições do solo, logo alcançam água e transbordam facilmente, não havendo portanto, nenhuma condição de higiene no mencionado local.

Tendo-se em vista o acima exposto e havendo interesse e necessidade de solucionar o problema, vimos solicitar as providencias de vossa senhoria, no sentido de que seja estudada a possibilidade da transferência dessas habitações para outro local salubre, em área determinada por esta prefeitura e em cooperação com essa CECAP. Ocorreu mesmo o caso de algumas famílias terem solicitado doação do material das habitações para erguê-las em outro local, o que não pode ser atendido, em vista, das construções serem em conjunto e de propriedade do Estado. (Processo Administrativo 1799/70).

O ofício foi recebido e respondido por João Lázaro de Almeida Prado, suplente de José Magalhães Prado $^{5}$ na superintendência da CECAP, e expõe que a autarquia não se responsabilizaria pela transferência das habitações para outro local, por falta de capital. A situação daqueles que foram realocados para um terreno de péssimas condições resultou no falecimento de uma criança. Face a este problema, dois arquitetos do Departamento de Obras Públicas do Estado de São Paulo (DOP), que foram comissionados na CECAP (Alfredo Paesani e Renato Nunes) esclareceram, por meio de um ofício enviado para a Prefeitura Municipal de Guarulhos, que as medidas tomadas pela autarquia foram de caráter provisório, e que, a longo prazo, seriam discutidas as possibilidades de remoção das habitações, com colaboração entre a CECAP e a Prefeitura, mas que como ação imediata aos problemas dos moradores apenas poderiam ser feitas drenagens do solo.

É possível perceber, nesse processo administrativo, conflitos entre moradores e o poder público, mas fica nítida a falta de assistência - tanto do Estado, que promovia habitação social para um setor específico -, mas também da Prefeitura de Guarulhos, que não conseguia atender certas demandas sociais instaladas no município.

\section{"Uma nova maneira de viver": Conjunto Habitacional Zezinho Magalhães Prado (1967-1972)}

No final do ano de 2014, foi inaugurado pela Prefeitura de Guarulhos o "Parque Vilanova Artigas", localizado no centro do bairro Parque CECAP. A 


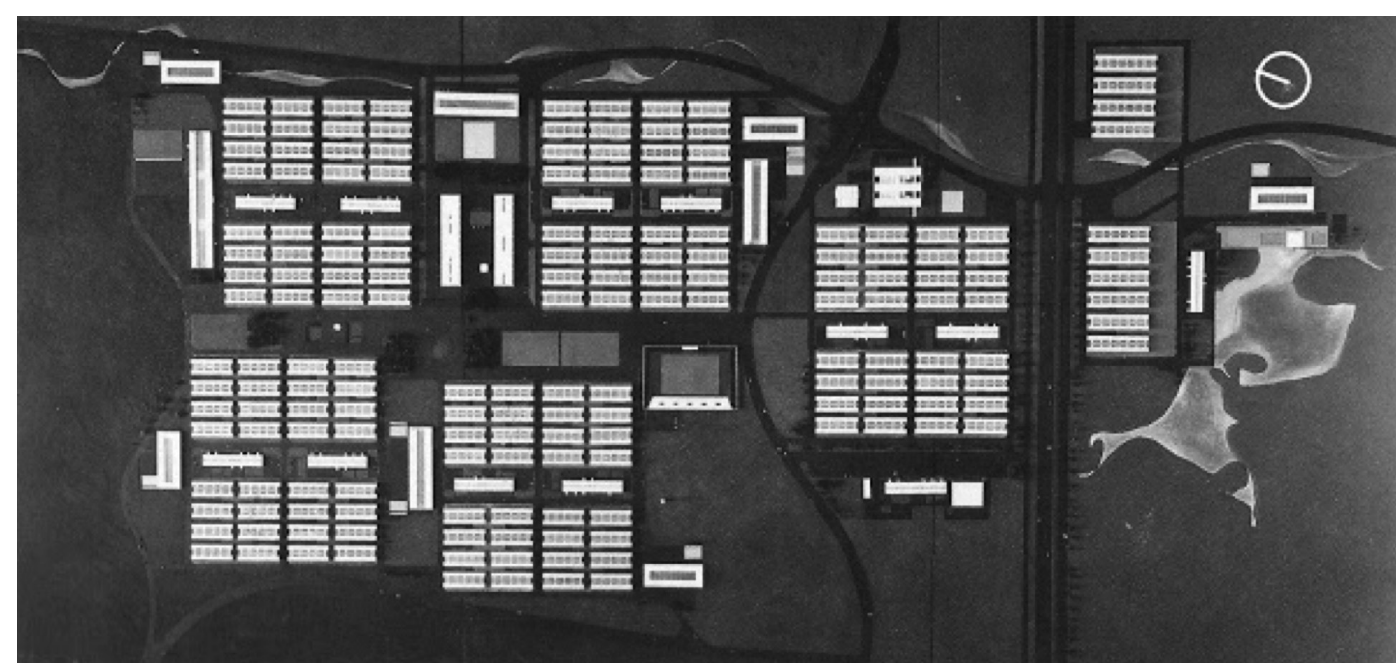

Figura 1: Imagem da maquete do conjunto habitacional de Guarulhos. Fonte: BASTOS, ZEIN, 2010, p. 174.

6 Disponível em <http:// www.guarulhos.sp.gov.br/ files1/AGENDA_AMBIENTAL_ FEV_15_OK.pdf >. Acesso em 05 de Maio de 2015

7 Como apontado na introdução deste artigo, nosso recorte está centrado na ação da CECAP quanto autarquia estadual. Após 1975, a autarquia foi substituída por uma empresa de capital misto, com ações do Estado e de empresários, mudando sua forma de ação no Estado - não possuía mais agente financeiro, sendo assim, os recursos para construção dos conjuntos eram da própria Companhia, obedecendo as normas do Banco Nacional de Habitação (BNH). Em Agosto de 1980 ela foi oficialmente desativada e sua estrutura foi incorporada em 1981 pela Companhia de Desenvolvimento de São Paulo (CODESPAULO), criada no governo de Paulo Maluf (DENIZO, 2007, p. 100) agenda ambiental da cidade apontou que este novo espaço está localizado em "um dos mais emblemáticos" bairros da cidade. ${ }^{6}$ Tal adjetivo define exatamente como o projeto do Conjunto Habitacional Zezinho Magalhães Prado (ou localmente conhecido como Parque CECAP), (1967) foi abordado por revistas, artigos, livros, dissertações e teses de arquitetura e urbanismo. O conjunto habitacional, um dos primeiros projetados pelos arquitetos Vilanova Artigas, Fábio Penteado e Paulo Mendes da Rocha (que coordenaram o escritório técnico com outros funcionários comissionados) é, segundo o arquiteto Miguel Antônio Buzzar (2014, p. 403), um projeto marcante do percurso intelectual de Artigas, bem como resultado da valorização da tecnologia construtiva em obras públicas de governos que visavam o desenvolvimento do país (KOURY, 2005).

Por ser uma obra de caráter simbólico, o conjunto acaba por vezes criando uma "sombra" na produção habitacional de Vilanova Artigas e da própria CECAP. Além dos conjuntos abordados neste artigo, o arquiteto projetou ainda os conjuntos habitacionais para as cidades de Mogi - Guaçu (1975), Marília (1976) e Jaú (1976) para a posterior fase da autarquia, a Companhia Estadual de Casas Populares, também chamada de CECAP. ${ }^{7}$ No en-tanto, por mais que a obra de Guarulhos tenha sido abordada em vários estudos, é preciso destacar que ainda é possível tratar sobre outras dimensões não exploradas sobre a mesma - a trajetória de planejamento, construção e apropriação do conjunto possuem passagens que foram pouco tratadas pelos estudiosos da habitação social e da obra de Vilanova Artigas. Além disso, se torna impossível separar a ação da CECAP do conjunto de Guarulhos - ele revela não apenas como Vilanova Artigas tratava o tema da habitação social, mas também como a autarquia queria ser conhecida pela população.

A construção de um conjunto de grande porte pela autarquia, marcaria então, todo o potencial da CECAP, além de criar uma imagem pela qual seria conhecida. Para isso, o então superintendente, José Magalhães Prado convidou, por intermédio de Ruy Gama, os arquitetos João Batista Vilanova Artigas, Fábio Penteado e Paulo Mendes da Rocha.

A proposta dos arquitetos foi montar um escritório técnico para realização do projeto independente da estrutura da CECAP. Como a autarquia era um órgão público, os primeiros arquitetos foram comissionados do antigo Departamento de Obras Públicas (DOP), Ruy Gama, (que já estava exercendo suas funções na CECAP como assessor de José Magalhães Prado e foi coordenador das atividades); o arquiteto Geraldo Vespasiano Puntoni e a arquiteta Maria Giselda Cardoso Visconti.

O escritório técnico, localizado na Avenida Brigadeiro Luís Antônio, ao lado da antiga sede da CECAP, foi 
${ }^{8}$ O montante de 10.560 unidades habitacionais para uma população de 55.000 habitantes partiu do problema habitacional de larga escala da Região Metropolitana de São Paulo. Guarulhos era uma área de grande atração de migrantes, por conta de sua expansão industrial a partir das medidas nacionais desenvolvimentistas, e não havia recebido nenhum programa habitacional estadual ou federal, além de encontrar-se em expansão imobiliária com a abertura de novos bairros devido à grande demanda da população migrante e operária (FICHER, 1972, s.p.)

Figura 2: Fotografia da maquete do conjunto habitacional, onde podemos notar as freguesias e os equipamentos urbanos projetados. Fonte: Acervo Iconográfico do Arquivo Público do Estado de São Paulo, 1969. aumentando o número de profissionais de acordo com o andamento dos trabalhos. Arnaldo Martino, Renato Nunes e Alfredo Paesani complementaram o escritório técnico, junto com uma Eugênia Paesani, para realizar estudos sócio econômicos (CERÁVOLO, 2007, p. 68). Além destes profissionais, Fábio Penteado convidou Stipan Dragutin Milic, responsável pela implantação de Zagreb, na antiga lugoslávia, para participar da equipe (ibidem, p. LV).

A linha de raciocínio para a elaboração do projeto foi definida por Artigas, segundo a arquiteta Sylvia Ficher (antiga estagiária do grupo), como

Tratando-se de equacionar em padrões mais atualizados o problema da habitação, o importante é reconhecer que a casa não termina na soleira da porta. Ao contrário, ela se liga aos recintos, aos espaços, aos edifícios e locais, onde se praticam esportes, onde se reza e onde se aprende a ler e a cultivar o espírito, para penetrar o conhecimento da cultura e da ciência. O lar se liga ao hospital, à escola como aos teatros e aos cinemas, em um verdadeiro sentido de comunidade. (FICHER, 1972 , s. p.)
Seguindo o pensamento em que "a casa não termina na soleira da porta" o grupo projetou, além das unidades habitacionais para os trabalhadores, um sistema completo de equipamentos públicos e privados para utilização de seus moradores. O projeto visava a construção de 10.560 unidades habitacionais para uma população de 55.000 habitantes. ${ }^{8}$ Os edifícios, critério adotado pela CECAP para conjuntos habitacionais em regiões de grande população, eram organizados em três andares sob pilotis, cada bloco com 60 unidades habitacionais.

Houve a concepção de organizar os blocos em um conceito de freguesias, semelhante ao conceito de unidade de vizinhança e a superquadra de Lucio Costa. Esta denominação partia da história da formação dos territórios durante a época de colo-nização (BUZZAR, 2014, p. 406). As freguesias seriam formadas por 1.920 unidades habitacionais mais equipamentos públicos e particulares desenvolvidos pelo escritório técnico, sendo que sua principal característica era construir um espaço de convivência entre os moradores do conjunto, sem delimitação de espaços de cada um dos condomínios, ou seja, nenhuma das freguesias teria grades ou espaços fechados.

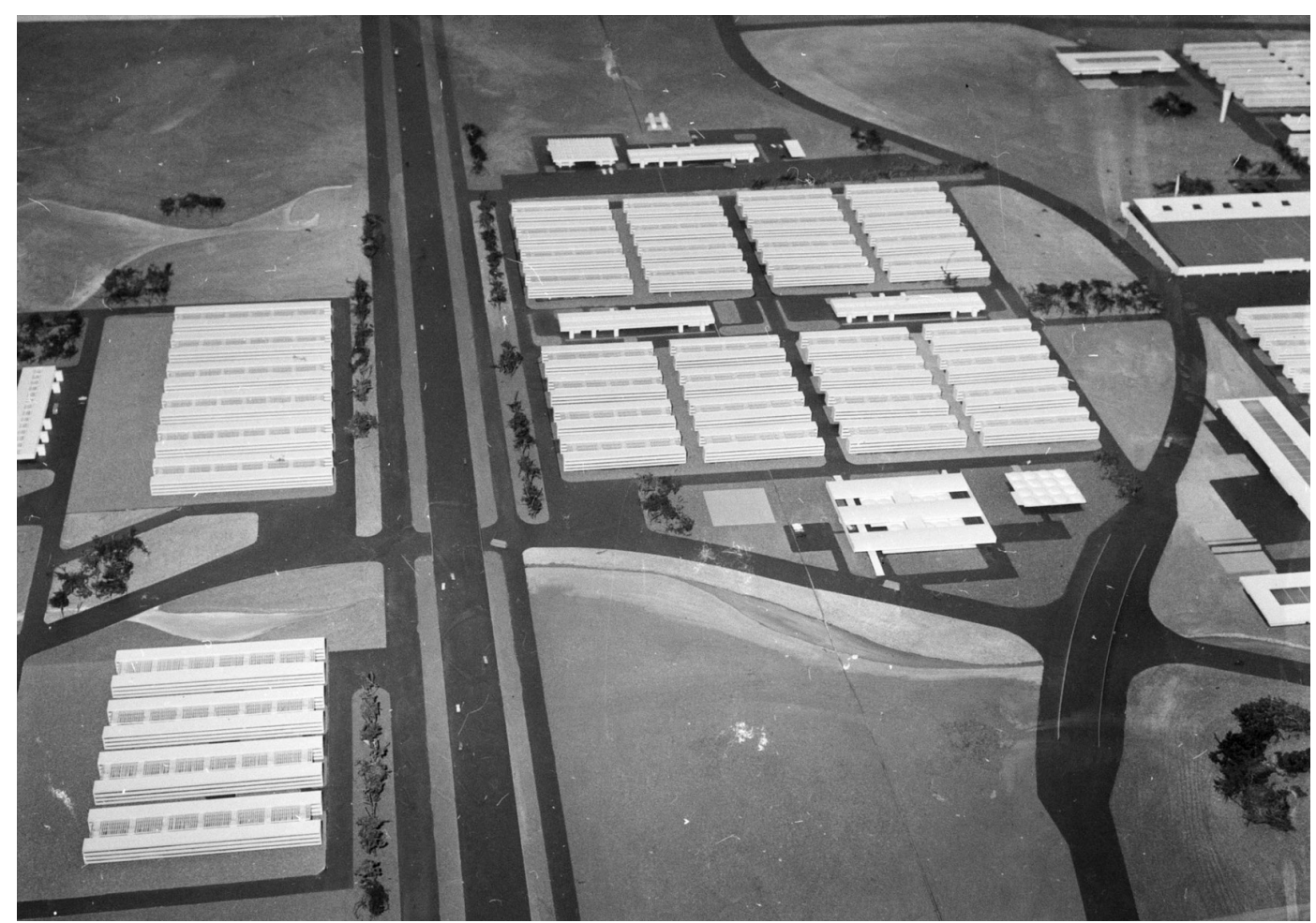



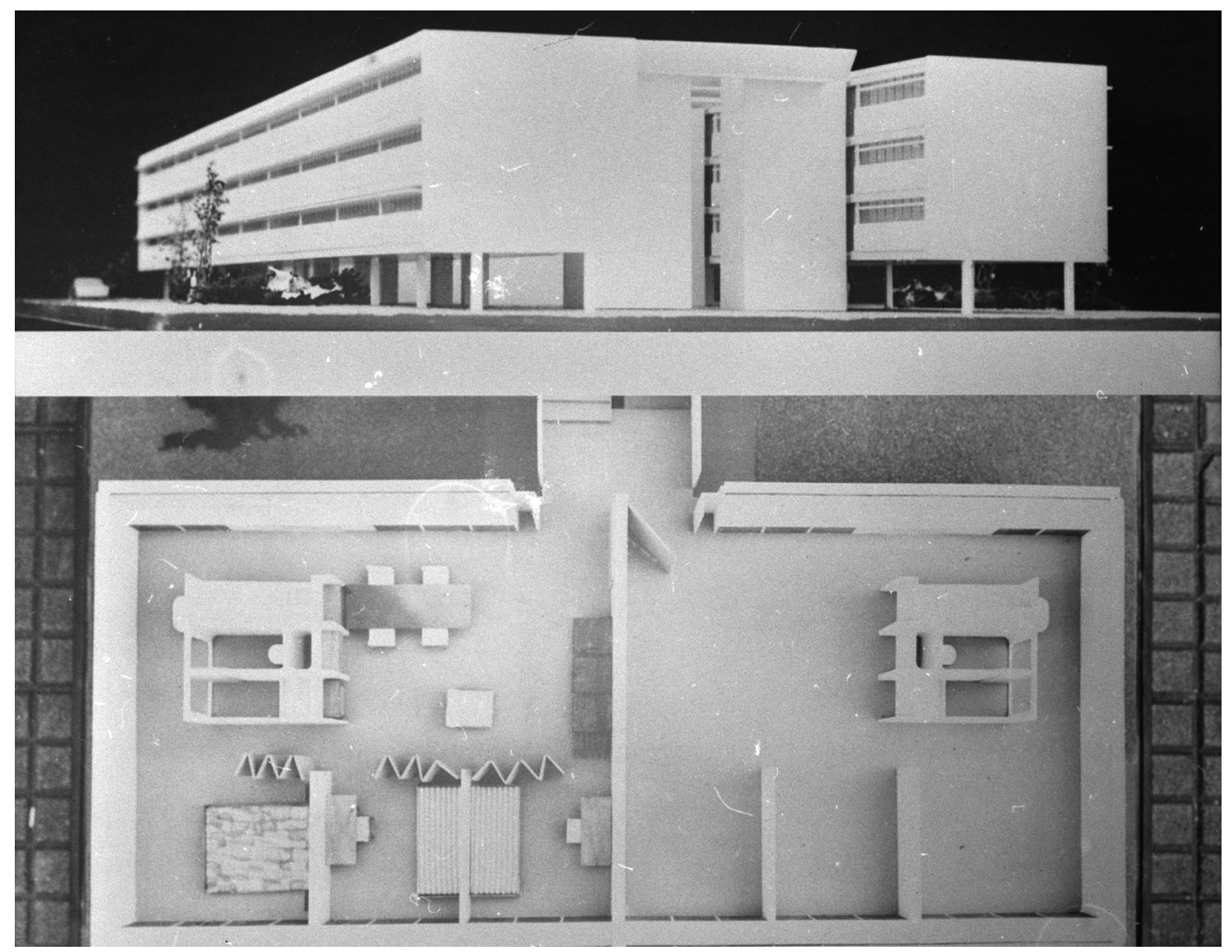

Figura 3: Fotografia da maquete do apartamento. Fonte: Acervo Iconográfico do Arquivo Público do Estado de São Paulo, 1969.

${ }^{9}$ Durante a formulação do projeto, o arquiteto Fábio Penteado teve a ideia de adicionar, além dos armários, equipamentos domésticos, como fogões, geladeiras, que se adaptavam à estrutura do apartamento e a moradores de renda baixa. A família de Penteado, possuía na época a empresa DAKO de equipamentos domésticos na cidade de São Carlos, que chegou a fazer protótipos de fogões para os apartamentos. Porém, Eugenia Paesani, socióloga da equipe fez um levantamento das peças de consumo dos futuros moradores do conjunto, e constatou que a classe que iria morar no conjunto já possuía tais equipamentos e que eram os principais clientes de lojas de mobiliário (CERÁVOLO, 2007, p. VIII).
O conjunto previa a construção de escolas que atenderiam uma demanda não apenas de seus moradores, mas também de bairros vizinhos, visando, assim, melhorar o déficit de matrículas da cidade de Guarulhos. O projeto educacional, elaborado por Celso Lamparelli, Maiumy Souza Lima e Alice Gonzaga (CERÁVOLO, 2007, p. 68), previa a criação de 6 grupos escolares, para alunos dos 6 aos 16 anos, com programação de 192 salas de aula para atender a demanda de 13.420 estudantes e 1 escola industrial (ensino técnico) para adolescentes com 21 salas de aula, para atender a 1.460 alunos (FICHER, 1972, s.p.).

Os equipamentos públicos idealizados no projeto foram um hospital geral com 200 leitos, pronto socorro com ambulatório, centro de saúde e posto de puericultura. Além destes, um estádio com capacidade para 15.000 pessoas, 2 salas de cinema, teatro, igreja, clube e um entreposto de abastecimento central, além de várias unidades de comércio particular nas freguesias. No projeto era previsto, ao lado da área do estádio um estacionamento e um terminal de linhas de transporte público. Também foram pensadas a construção de um gasômetro e de uma caixa d'agua central, para abastecimento das unidades. No caso do gasômetro, previu-se a dificuldade dos moradores em carregarem botijões de gás, então todos os apartamentos possuiriam gás encanado.

Os apartamentos foram projetados levando em conta possíveis melhorias de vida cotidiana para os futuros habitantes do conjunto. No projeto, o apartamento de área equivalente a $64 \mathrm{~m}^{2}$, possuía janelas corridas, produzidas e instaladas pelo Liceu de Artes e Ofícios (CERÁVOLO, 2007, p. 103); piso constituído de um tipo de manta vinílica, que se adaptava às paredes, que formam uma planta livre - divisórias de gesso, que permitiam flexibilidade dos cômodos do apartamento, de acordo com os hábitos e tamanho das famílias, sendo as únicas partes fixas o banheiro, a lavanderia e a bancada da cozinha. Cada apartamento possuía uma sala de estar, cozinha, lavanderia, banheiro e três quartos. Além disso, as paredes fixas do apartamento possuem uma solução prática para a economia de espaço, com armários embutidos. ${ }^{9}$ 
Propostas para "uma nova maneira de viver": Vilanova Artigas e a ação habitacional da CECAP (1967-1973) |

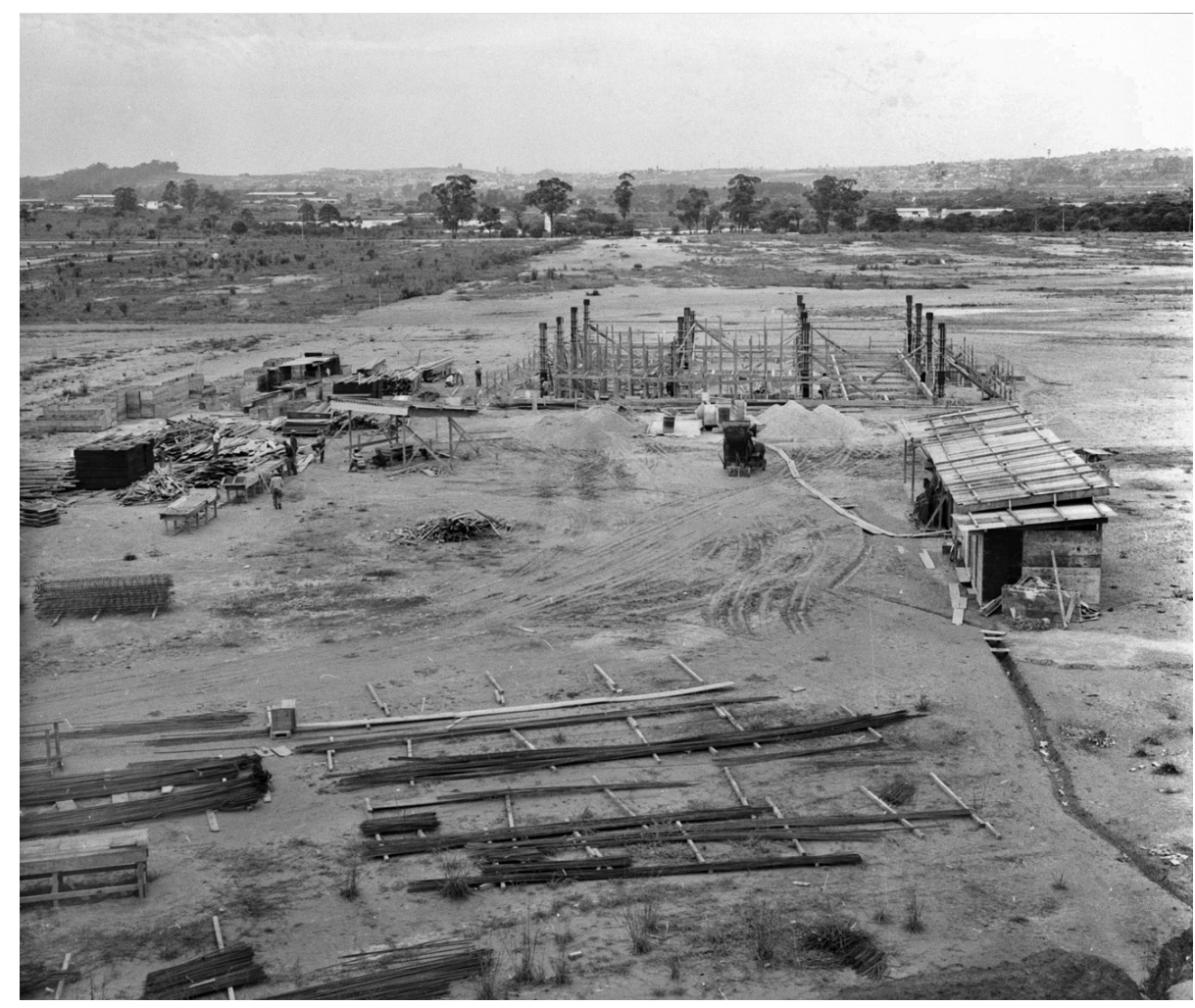

Figura 4 (topo): Fotografia do canteiro de obras dos primeiros blocos do conjunto. Fonte: Acervo Iconográfico do Arquivo Público do Estado de São Paulo, 1971.

Figura 5: Fotografia do canteiro de obras dos primeiros blocos do conjunto. Fonte: Acervo Iconográfico do Arquivo Público do Estado de São Paulo, 1971.

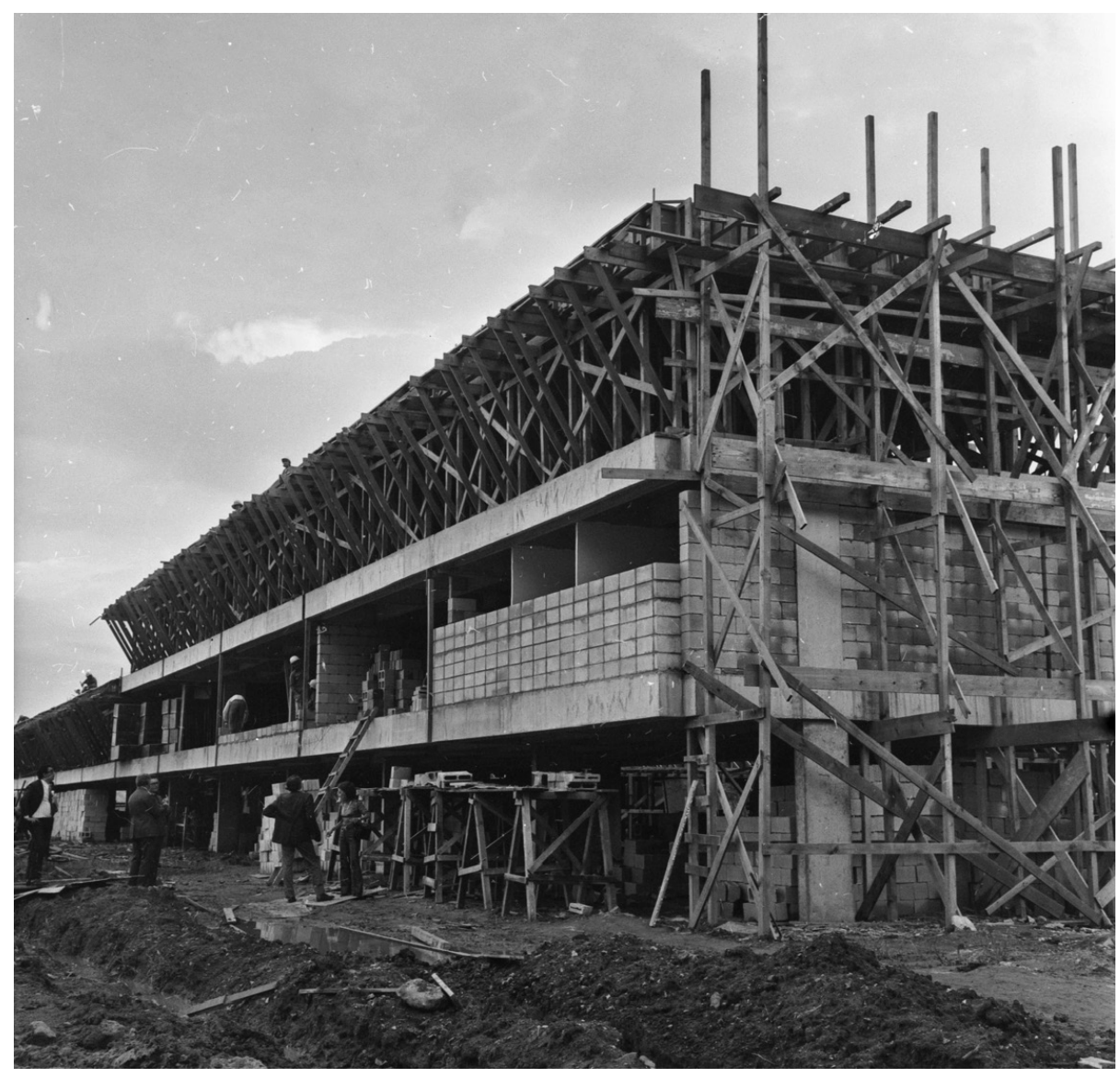


Uma das características de maior destaque do projeto foi o cálculo de execução da construção com utilização de elementos pré-fabricados para otimização do tempo e diminuição do custo da unidade habitacional. Porém, essa medida foi inviabilizada pela liberação de construção de apenas 480 unidades habitacionais pelo Governo Estadual (FICHER, 1972, s.p.). Para além do problema de liberação das unidades que seriam construídas, alguns processos administrativos da Prefeitura de Guarulhos demonstram alguns impasses entre as imposições da prefeitura para a construção e o projeto que foi realmente construído no terreno.

Uma série de ofícios juntos à Prefeitura de Guarulhos revelam algumas irregularidades para a concessão do Habite-se das primeiras 480 unidades do conjunto. Em 18 de Janeiro de 1972, a CECAP pediu a Prefeitura Municipal de Guarulhos a vistoria e concessão para uso das primeiras unidades habitacionais construídas. Quase um mês após o pedido, o engenheiro responsável pela vistoria da obra, enviou relatório ao Diretor do Departamento de Obras do município, constatando irregularidades na construção (a construção de 3 dormitórios, quando haviam sido aprovados apenas 2 e problemas na observância do Código Sanitário do Estado).

Apesar da construção possuir, segundo o ofício, algumas irregularidades, em leis estaduais sobre a disposição de seus espaços, além de uma alteração no projeto das unidades habitacionais, sendo que o construído não havia sido aprovado pela Prefeitura de Guarulhos, o oficio tem um caráter de não salientar tais elementos como um aspecto negativo, mas dar destaque às necessidades de Guarulhos - a cidade precisava de um conjunto habitacional, já que que encontrava em um momento de abertura de loteamentos para poder atender a demanda de migrantes que chegavam na cidade, atraídos pelo seu parque industrial (GUERRA, 2011, p. 26). Segue o parecer do Habite-se, transcrito a seguir

Considerando que o empreendimento está diretamente ligado a autarquia CECAP cujo objetivo restringe-se tão somente a suprir as deficiências do cruciante problema habitacional, propiciando aos membros dessa comunidade, ou seja, a classe fabril, a oportunidade de possuir moradia própria.
... que o dito conjunto já se encontra dotado dos benefícios primordiais à regra favorável da boa moradia, ou seja, rede de água, esgoto, iluminação.

... que esse empreendimento representa grande significação, constituindo um esforço do Governo Estadual dentro do plano nacional de suprir o déficit do problema habitacional.

... que a elaboração dos projetos foi destinado a um técnico altamente recomendado, de renome internacional amplamente citado nos meios da tecnologia moderna. (Relatório do Habite-se do Conjunto Habitacional Zezinho Magalhães Prado, 1972. s.p.)

Segundo o processo administrativo descrito e transcrito acima, no mesmo dia em que este parecer foi enviado, a Prefeitura Municipal de Guarulhos aprovou o uso das novas unidades habitacionais. Fica perceptível que de nenhuma forma a Prefeitura iria proibir ou postergar o uso do conjunto, mesmo com irregularidades - a Prefeitura não possuía meios para promover habitação para a classe trabalhadora mais evidente em sua paisagem, e mesmo que as primeiras unidades tivessem problemas técnicos, a obra estava dentro de um programa político de ações do Estado de São Paulo.

A entrega das unidades habitacionais ocorreu em julho de 1972. Ao se mudarem para o novo empreendimento da CECAP, os novos moradores se depararam com um conjunto em construção, sem nenhum equipamento público ou privado construído, em um local sem infraestrutura, distante do centro da cidade e com difícil acesso a parte comercial do bairro de Cumbica. Em média, os primeiros moradores eram em sua maioria jovens casais, que haviam acabado de formar um núcleo familiar e procuravam realizar o sonho da casa própria.

A quantidade de jovens famílias que se mudaram para o novo condomínio foi de tal forma predominante, que em propagandas de venda dos apartamentos e chamadas para financiamento das unidades, explicitavam uma imagem de que o local era propício para novas famílias, com amplos espaços e convivência - que não era mais do que o espaço entre os blocos de apartamentos e o térreo livre. Apesar de tais características serem elevadas como qualidades pela publicidade produzida pela 
10Jornal Folha de S. Paulo. "Ninguém melhor do que ele para contar o que é a CECAP". Caderno llustrada. São Paulo. Set. de 1973.

11Para além dos conjuntos projetados por Vilanova Artigas, se destacam os conjuntos de Serra Negra (Abrahão Sanovicz), Taubaté (do escritório de Jerônimo Bonilha e Israel Sancovski) e de Piracicaba (Dan J. Antonio).

12Disponível em <http:// www.americana.sp.gov. br/v6/americanaV6_index. php?it=40\&a=resumo Historico_imigracaoAmericana>. Acesso em 05 de Maio de 2015. autarquia, muitos problemas se fizeram presentes no cotidiano dos moradores, como a falta de locais para compras de alimentos, falta de creches, bancos e transporte público, além das vias municipais não serem asfaltadas. Da falta de equipamentos e a construção em partes do conjunto habitacional, a identidade do bairro surgiu, sendo que seu principal alicerce era a cooperação entre os moradores (GUERRA, 2011).

\section{Uma nova CECAP para o interior paulista}

Após a experiência do grupo de arquitetos no conjunto habitacional de Guarulhos para a CECAP, Artigas e Fábio Penteado buscaram nas cidades do interior apoio para a construção de novos conjuntos habitacionais, como nos aponta Gabriel Cunha (2009, p. 86). É possível observar que, dentro da trajetória da CECAP como autarquia que promovia habitação social, foi após a construção das primeiras unidades do Conjunto Habitacional Zezinho Magalhães Prado que esta ganhou fôlego para a produção de moradia, porém, com um foco de atuação no interior do Estado, dentro do plano de Interiorização do Desenvolvimento industrial do Governo do Estado, como demonstra o texto da propaganda da autarquia

A CECAP representa a preocupação do Governo do Estado de São Paulo em oferecer uma solução ideal para o problema da habitação. Dentro do programa de interiorização do Governo do Estado, a CECAP constrói casas e apartamentos no Interior, financiados pela Caixa Econômica Estadual. A CECAP localiza seus projetos especialmente nas regiões em Desenvolvimento, atendendo à grande demanda de moradias. Ela não se limita a construir casas e apartamentos bonitos e confortáveis. Projeta também conjuntos integrados, com amplas áreas verdes, onde os moradores encontram todo o necessário à vida familiar: escolas, centros de saúde, centro comercial, cinemas e clubes. Além dos moradores, toda a comunidade é beneficiada pela CECAP. Seus projetos modelares influenciam os incorporadores locais, que passam a seguir seu alto nível de construção. Todo o problema habitacional da região é praticamente resolvido, pois os conjuntos integrados da CECAP atendem em geral, a milhares de famílias. Como são autosuficientes, as pessoas fazem suas compras neles mesmo, deixando de ir ao centro e assim evitando seu congestionamento. A mais recente obra da CECAP - O Parque CECAP é um bom exemplo de que está fazendo este órgão da administração estadual..$^{10}$

Com esta propaganda divulgada no jornal Folha de S.Paulo, podemos notar que a prioridade em atuar na região metropolitana de São Paulo foi substituída pela interiorização do desenvolvimento urbano e econômico do Estado, com a construção de conjuntos. É possível notar também que o conjunto de Guarulhos, referido na propaganda como "Parque CECAP", é símbolo e imagem daquilo que a autarquia queria ser conhecida, salientando a qualidade do projeto do grupo de Artigas.

Durante a década de 1970 é perceptível que para os conjuntos habitacionais de grande porte, com mais de 120 unidades habitacionais, a CECAP delegava o projeto para escritórios de arquitetura e urbanismo, baseando sua escolha nos currículos dos arquitetos ${ }^{11}$, para os demais conjuntos, a autarquia possuía um "projeto carimbo", elaborado pela Divisão de Engenharia. No caso dos arquitetos que trabalharam no conjunto de Guarulhos, mais especificamente Vilanova Artigas e Fábio Penteado, a autarquia ofereceu uma certa "liberdade", não apenas para a elaboração do projeto, mas também para a escolha das cidades em que os conjuntos iriam se inserir.

Dos conjuntos produzidos no interior, o conjunto de Americana (1972, não executado) e o conjunto de Jundiaí (1973) foram projetados por Artigas e Fabio Penteado e são experiências interessantes para análise da postura política sobre habitação social, além de serem elaborados e construídos na fase em que a CECAP ainda era reconhecida administrativamente como uma autarquia governamental.

\section{Conjunto Habitacional CECAP - Americana (1972)}

O conjunto habitacional de Americana foi projetado em 1972, para uma demanda de cerca de dois mil moradores. A cidade, reconhecida pelo seu polo têxtil, passou por um aumento populacional entre as décadas de 1960 e 1970 12 , momento o qual Artigas e Fábio Penteado procuraram apoio da Prefeitura de Americana para a construção de um conjunto habitacional. 


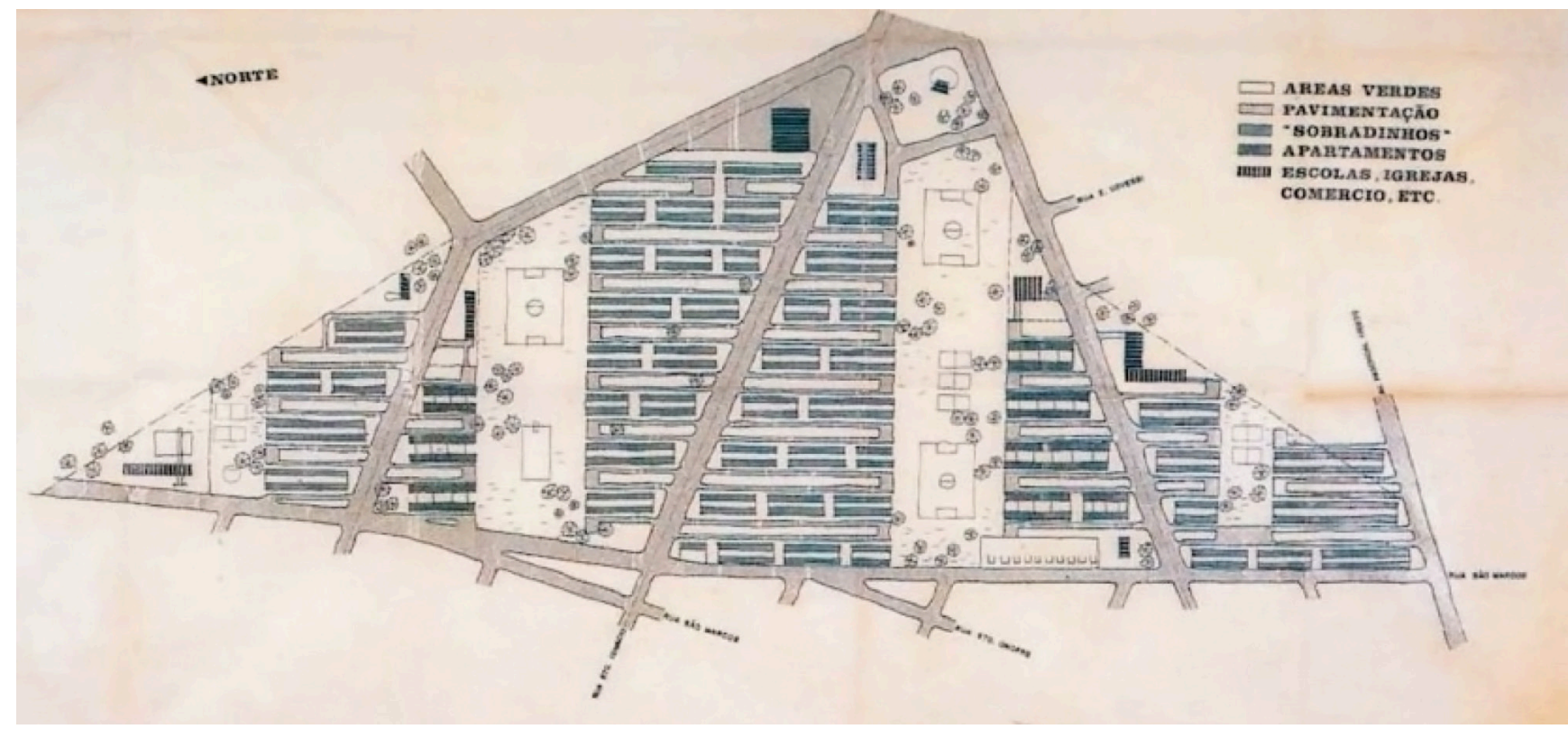

Figura 6: Imagem do projeto do conjunto habitacional da CECAP para a cidade de Americana (1972). Fonte: CUNHA, 2009, p. 87
O projeto seguiu a mesma proposta do conjunto de Guarulhos: blocos com três pavimentos, sustentados por pilotis, alinhados ortogonalmente e em pares, com uma solução de circulação vertical que dispensa corredores internos aos andares dos blocos, sendo que a diferença entre este conjunto e o de Guarulhos está na substituição das escadas por rampas. 0 conjunto também previa a implantação dos blocos de apartamentos em freguesias, com a instalação de elementos como escola, igreja, equipamentos de lazer, área verde e comércio disperso dentro das quadras (CUNHA, 2009, p. 85).

Uma nova proposta para o conjunto de Americana seria, além da construção dos blocos de edifícios, a implantação de sobrados em pares, geminados, com dois dormitórios, quintal e garagem coberta para dois automóveis. Na planta, os sobrados possuem três níveis: o andar térreo com a garagem, cozinha, sala, área de serviço e quintal; o nível intermediário com o banheiro; e o último nível com dois dormitórios. A solução do banheiro no nível intermediário permitia que o mesmo servisse aos dois níveis e simplificaria a cobertura (laje de concreto) devido ao abrigo que o desnível criaria para a caixa d'agua. Os sobrados estariam dispostos em sequência longitudinal, formada por seis sobrados. Neste conjunto novo proposto por Artigas e Fábio Penteado, também estariam presentes elementos industrializados e as paredes hidráulicas, como no conjunto de Guarulhos (ibidem, p. 82).

A construção do conjunto de Americana não ocorreu por causa da localização escolhida para a implantação. Fábio Penteado tinha a proposta de utilizar um terreno junto à uma represa da cidade, de fácil acesso e próxima à cidade. Segundo depoimento do arquiteto, esta experiência foi frustrada pelo prefeito, pois como o conjunto se destinava a moradia de operários, era inconcebível estes morarem próximo a uma área de lazer - a célebre Praia dos Namorados - e distante da área de produção. Segundo depoimento

O prefeito de Americana, o governo, foi radicalmente contra no começo. Eu me lembro que propunha a organizar os conjuntos de habitação de forma intermunicipal. Pois alguns municípios eram muito perto, como Americana e Campinas. Porque o custo de implantar uma obra destas é muito grande. Se você conseguisse fazer um projeto a ser desenvolvido ao longo do tempo, tendo que ter viabilidades de transporte, de condução de água e de esgoto, o lixo, etc, se você concentrasse num lugar só era ruim. $E$ eu propunha na beira da lagoa de Americana, no lado oposto à cidade, mas eram poucos minutos de distância. Lembro-me que eu fiz, que eu coloquei, na Câmara Municipal, a importância de ter a formação de 
uma cidade ao lado de uma "água bonita", e colocar junto da habitação o lazer próximo, que era uma tese mundialmente conhecida e desenvolvida na época, que chegou ao Brasil pela UIA (União Internacional de Arquitetos) que captou tudo que se discutia de modernidade. O prefeito ficou alucinado de ódio. $O$ lazer para operários. Operário tem que morar perto da fábrica! Foi uma vergonha. (CUNHA, 2009, p. 84).

O depoimento demonstra um discurso por parte do prefeito de Americana de separar a moradia dos operários do espaço de lazer da cidade, desqualificando o espaço da moradia como um local que que liga a outros espaços de convivência que não o do labor.

\section{Conjunto Habitacional Parque CECAP - Jundiaí (1973)}

A cidade de Jundiaí, localizada no interior do Estado, estava na esteira do Plano de Desenvolvimento Industrial do Estado de São Paulo durante a década de 1970, plano o qual a CECAP participava, como mencionado, na promoção de habitação aos trabalhadores dos novos polos industriais instalados nas cidades do interior. A cidade de Jundiaí possui um grande parque industrial, que assim como Guarulhos, se desenvolveu a partir da instalação do ramal de ferrovia e da instalação da estrada velha de Campinas e da Rodovia Anhanguera (RUPRECHET, 2003, p. 104).

Em 1973, a CECAP desapropriou uma área com

Figura 7: Planta de corte do conjunto habitacional de Jundiaí. Fonte: CUNHA, 2009 um local afastado da parte urbanizada da cidade e em frente a um clube de campo. A área, apesar de distante, estava situada em um dos vetores de crescimento de Jundiaí e diminuía o investimento inicial da autarquia no custo do terreno (ibidem, p. 117). Fábio Penteado, em depoimento, comentou que a parceria entre a CECAP e a Prefeitura de Jundiaí, que possuía um ponto de vista diferente da experiência mal sucedida de Americana

Foi um apoio mais interessante e simpático do prefeito, da prefeitura. Certamente o prefeito tinha uma maneira de pensar mais ligada a uma coisa mais desejada sob nosso ponto de vista. Uma visão progressista. Cabendo à prefeitura uma parte do compromisso de gerar melhores condições de vida para os trabalhadores (CUNHA, 2009, p. 82).

Em 1972 a CECAP solicitou que fosse elaborado pelo escritório de Vilanova Artigas, um projeto executivo para uso de todo o terreno, porém, no ano seguinte pediram um projeto para construção de apenas algumas unidades, localizadas na parte leste do terreno.

A parte leste do terreno utilizado para a primeira etapa do conjunto possuía topografia acidentada, o que resultou na construção de blocos de apartamentos unidos por quatro rampas desniveladas entre si e que se apoiam sobre quatro patamares escalonados, acomodando-se ao declive do terreno. Em comparação ao Conjunto Zezinho Magalhães Prado, este possui rampas ao invés de escadas e uma distância maior entre os blocos de apartamento. Segundo Ruprechet (2003, p. 119), isso significou "aumentar a privacidade de cada apartamento e proporcionou aos moradores mais conforto para acessar suas moradias".

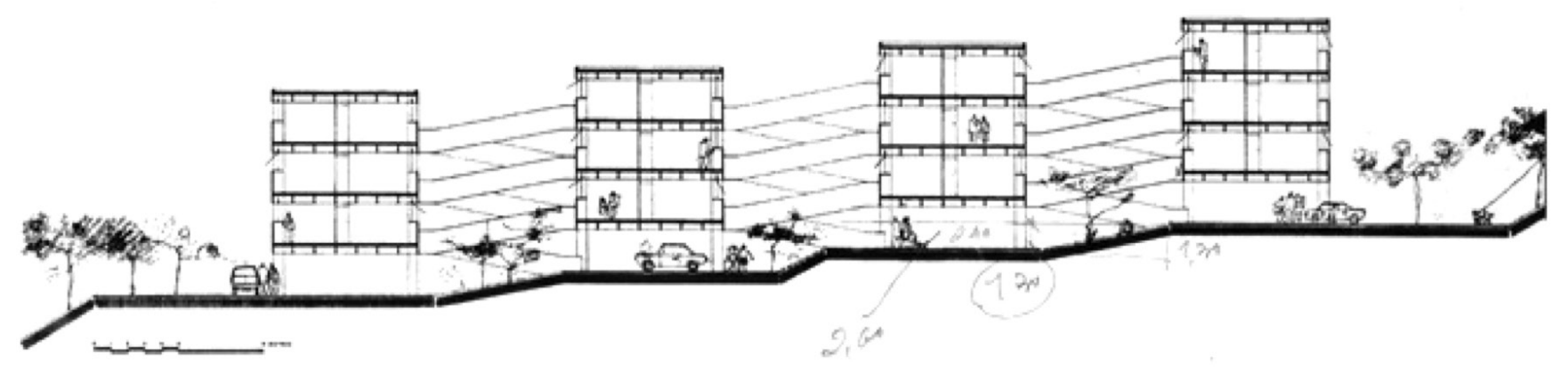




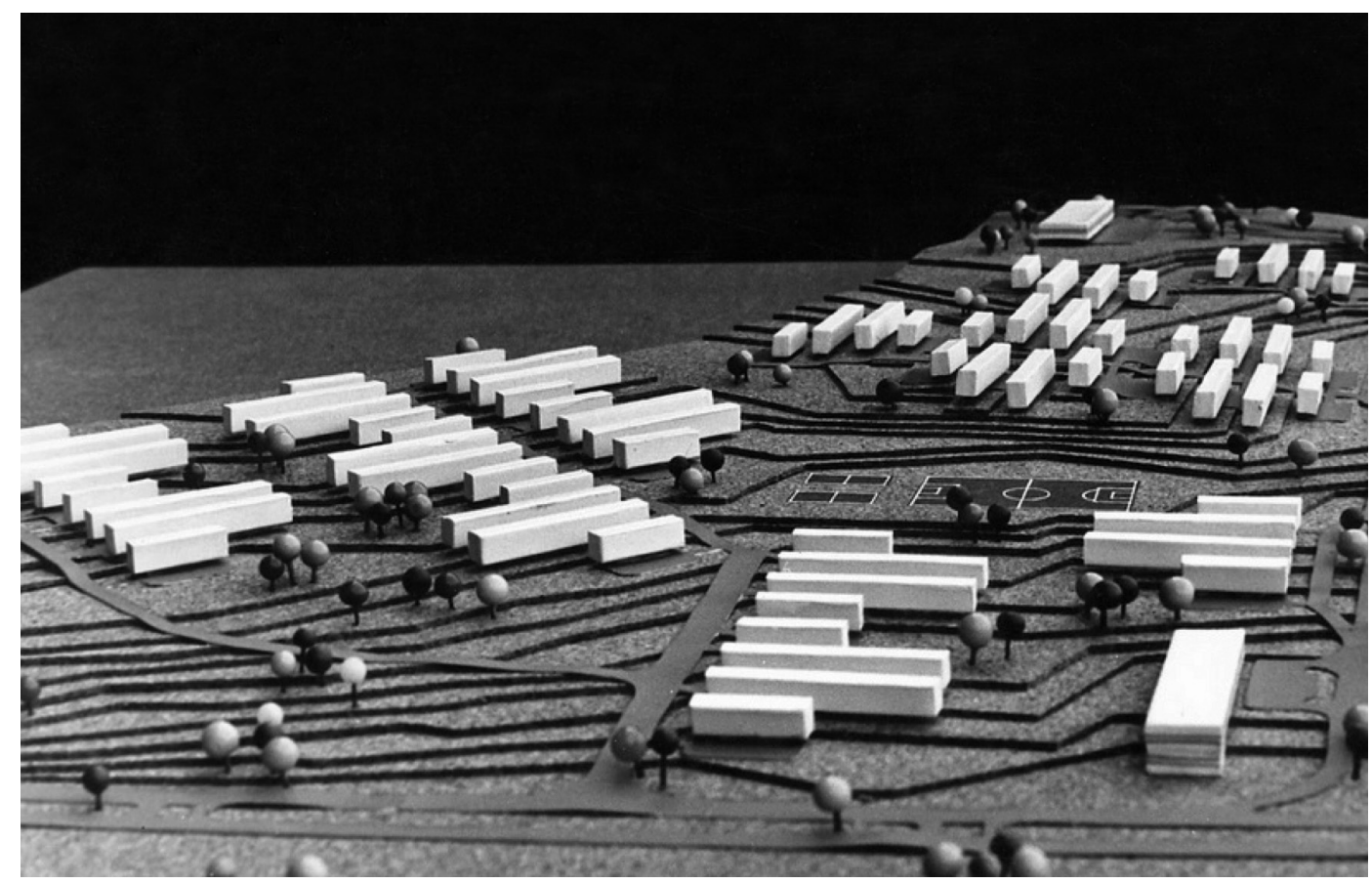

Figura 8: Fotografia da maquete do conjunto habitacional de Jundiaí, utilizando a área total. Fonte: <vilanovaartigas.com>. Acesso em 05 de Maio de 2015
13 É importante frisar que, apesar de estarem no mesmo terreno, os conjuntos habitacionais além de possuírem tipologias arquitetônicas diferentes, possuem nomes diferentes. Ruprechet (2003) sinalizou em sua dissertação de mestrado que o conjunto projetado por Artigas, é conhecido na cidade como "Parque CECAP", já o conjunto da CDHU possui o nome de "Morada das Vinhas"
No desenho do bloco, foi optado pela inversão de cada módulo com oito apartamentos por andar, em forma de "H". Cada bloco possuía 24 apartamentos por andar, distribuídos em três pavimentos sobre pilotis, com o total de 72 apartamentos por bloco. A primeira etapa de construção do conjunto habitacional foi composta por seis condomínios com um bloco cada um, gerando no total 432 unidades habitacionais para uma população de 2.160 habitantes.

Segundo Ruprechet (2003, p. 132), primeiramente o projeto estrutural era de construção convencional, porém Artigas convenceu a CECAP a utilizar peças pré-moldadas, produzidas pela Servix Engenharia S.A., como as paredes externas, as lajes e as rampas, o que facilitou o processo construtivo. Outros elementos, como os caixilhos, foram fabricados pelo Liceu de Artes e Ofícios, seguindo a experiência do conjunto habitacional Zezinho Magalhães. No processo de construção desse conjunto, Vilanova Artigas e sua equipe conseguiram colocar algumas peças pré-moldadas in loco. No projeto cromático das fachadas, Artigas propôs a criação de uma variedade de cores sobre a face exterior dos blocos, contrastante com o concreto das rampas. O desenho tinha semelhanças com o logotipo da autarquia (criada por João Carlos Cauduro e inspirado nas bandeirinhas dos quadros de Alfredo Volpi), mas tal pintura não foi concretizada porque não facilitava o trabalho de pintura (RUPRECHET, 2003).

O conjunto de 432 unidades foi construído entre 1976 e 1978, quando a autarquia já havia mudado sua estrutura administrativa. Tardiamente o resto do terreno foi utilizado pela Companhia de Desenvolvimento Habitacional e Urbano (CDHU) para construção do restante do conjunto habitacional ${ }^{13}$, porém, estes novos apartamentos seguiram outra tipologia arquitetônica. A CDHU optou por construir seu edifício padrão, o modelo denominado VG22A (de autoria do arquiteto Luiz Flávio Gaggetti), pois comparado ao projeto de Artigas, que priorizava o espaço coletivo, com uma baixa densidade, o modelo padrão estava dentro da faixa de custo que a empresa pública poderia financiar (ibidem, p. 136).

\section{Considerações finais}

Iniciamos este artigo com a frase publicitária "A CECAP não constrói apenas casas. Constrói uma nova maneira de viver". Após revisitarmos a contribuição de Vilanova Artigas nos conjuntos promovidos pela 
autarquia, é possível compreender certos aspectos da trajetória da CECAP na formulação de uma política habitacional para o Estado de São Paulo.

A figura do arquiteto foi importante dentro da instalação definitiva da autarquia no setor habitacional. Com uma produção pequena e com projetos simples, a CECAP visava não apenas "cons-truir uma nova maneira de viver", mas principalmente construir uma imagem de si-como autarquia governamental que elaborava projetos habitacionais de qualidade, diferente da produção que começava a ganhar espaço dentro do sistema BNH. Deste modo, compreendemos que ninguém mais do que Vilanova Artigas para realizar projetos que fossem de caráter excepcional.

A concepção urbanística do arquiteto foi, para os três projetos abordados neste artigo, baseada na ideia de que a unidade habitacional "não termina na soleira da porta", onde os projetos, além de pensados em utilizar elementos industrializados, tinham como preocupação integrar o conjunto a cidade, e vice-e-versa, criando espaços de sociabilidade e integração da comunidade. Podemos dizer que, de fato, o arquiteto produziu "uma nova maneira de viver", próxima (no sentido de qualidade arquitetônica e urbanística) as propostas dos antigos Institutos de Aposentadoria e Pensões (IAPs) e do Departamento de Habitação Popular (DHP).

Contudo, mostramos que as dimensões que en-volvem as obras de Artigas para a CECAP passaram por alguns obstáculos políticos, alguns se refletiram imediatamente no modo construtivo das obras - a aprovação de apenas uma parcela do Conjunto Habitacional Zezinho Magalhães Prado teve impacto na realização de apenas uma parte do projeto completo, utilizando método convencional para construção das primeiras 480 unidades habitacionais. Na cidade de Americana, a execução do projeto foi cancelada devido a posição política do prefeito da cidade, ao contrário do prefeito da cidade de Jundiaí, que aprovou a instalação do conjunto - porém, é preciso destacar que por mais que este último caso não se classifique como um "impasse" na obra, ele não deixa de mostrar uma posição política do prefeito da cidade, bem como a prefeitura de Guarulhos - ambas cidades estavam em um momento de expansão urbana e demográfica - a instalação de um conjunto habitacional com investimento estadual era mais do que necessária para ambas.

Podemos dizer então, que a dimensão política permeou toda a participação de Artigas no órgão habitacional Caixa Estadual de Casas para o Povo. Ora o Governo Estadual, representado pelas ações da autarquia (na escolha dos profissionais e local de instalação dos conjuntos), ora as posições políticas de municípios, limitaram o desenvolvimento dos projetos.

\section{Referências bibliográficas}

BASTOS, Maria Alice Junqueira; ZEIN, Ruth Verde. Brasil: Arquiteturas após 1950. São Paulo: Editora Perspectiva, 2010.

BONDUKI, Nabil. Origens da Habitação Social no Brasil: arquitetura moderna, lei do inquilinato e difusão da casa própria. São Paulo: Estação Liberdade, 2004.

BUZZAR, Miguel Antonio. João Batista Vilanova Artigas: elementos para a compreensão de um caminho da arquitetura brasileira, 1938 - 1967. São Paulo: Editora UNESP/ Editora Senac, 2014.

CAMARGO, Mônica Junqueira de. Poéticas da razão e construção: conversa de paulista. Tese (Livre Docência) - Faculdade de Arquitetura e Urbanismo, Universidade de São Paulo, São Paulo. 2009.

CERÁVOLO, Fabiana. A pré-fabricação em concreto armado aplicada a conjuntos habitacionais no Brasil: o caso do "Conjunto Habitacional Zezinho Magalhães Prado". Dissertação (Mestrado) - Escola de Engenharia de São Carlos, Universidade de São Paulo, São Carlos. 2007.

CUNHA, Gabriel Rodrigues. Uma análise a produção de Vilanova Artigas entre os anos de 1967 a 1976. Dissertação (Mestrado em Arquitetura e Urbanismo) - Escola de Engenharia de São Carlos, Universidade de São Paulo. São Carlos, 2009.

DENIZO, Valentina. Os produtos da política estadual de habitação na Região Metropolitana de São Paulo: elementos para análise de uma política metropolitana de habitação. Tese (Doutorado em Arquitetura e Urbanismo) - Faculdade de Arquitetura e Urbanismo, Universidade de São Paulo, São Paulo. 2007.

FICHER, Sylvia. Subsídios para um estudo do Conjunto Zezinho Magalhães. TGI (Graduação) - Faculdade de Arquitetura e Urbanismo, Universidade de São Paulo, São Paulo. 1972.

GUERRA, Tiago Cavalcante (org.). CECAP Guarulhos: Histórias, identidades e memórias. São Paulo: Scortecci, 2010.

KOURY, Ana Paula. Arquitetura Construtiva: proposições para a produção material da arquitetura contemporânea no Brasil. Tese (Doutorado) - Faculdade de Arquitetura e Urbanismo, Universidade de São Paulo, São Paulo. 2005. 
REVISTA DESENHO. São Paulo: Laboratório de Artes Gráficas da FAUUSP, v. 4. Maio de 1972.

RUPRECHET, Denise. Conjunto Habitacional Jundiaí - A: dois modos de arquitetar. Dissertação (Mestrado em Arquitetura e Urbanismo) - Faculdade de Arquitetura e Urbanismo, Universidade Presbiteriana Mackenzie. São Paulo, 2003.

VIEIRA, Edson Trajano. Industrialização e políticas de desenvolvimento regional: o Vale do Paraíba paulista na segunda metade do século XX. Dissertação (Mestrado e História Econômica) - Faculdade de Filosofia, Letras e Ciências Humanas, Universidade de São Paulo, São Paulo. 2009. 